\title{
Seismic zones for Azores based on statistical criteria
}

\author{
M. C. M. Rodrigues ${ }^{1}$ and C. S. Oliveira ${ }^{2}$ \\ ${ }^{1}$ Faculdade de Ciências e Tecnologia, Caparica, Portugal \\ ${ }^{2}$ Instituto Superior Técnico, Lisbon, Portugal \\ Correspondence to: M. C. M. Rodrigues (mcmr@fct.unl.pt)
}

Received: 6 December 2012 - Published in Nat. Hazards Earth Syst. Sci. Discuss.: Revised: 18 July 2013 - Accepted: 23 July 2013 - Published: 24 September 2013

\begin{abstract}
The objective of this paper is to define seismic zones in the Azores based on statistical criteria. These seismic zones will likely be used in seismic simulations of occurrences in the Azores Archipelago.

The data used in this work cover the time period from 1915 to 2011. The Azores region was divided into $1^{\circ} \times 1^{\circ}$ area units, for which the seismicity and the maximum magnitudes of events were calculated.

The seismicity, the largest earthquakes recorded and the geological characteristics of the region were used to group these area units because similar seismic zones must delineate areas with homogeneous seismic characteristics. We have identified seven seismic zones.

To verify that the defined areas differ statistically, we considered the following dissimilarity measures (variables): time, size and seismic conditions - the number of seismic events with specific characteristics.

Statistical tests, particularly goodness-of-fit tests, allowed us to conclude that, considering these three variables, the seven earthquake zones defined here are statistically distinct.
\end{abstract}

\section{Introduction}

The Azores Archipelago is located at the triple junction of the Mid-Atlantic Rift, where the Eurasian, Nubian, and American Plates meet.

The intense seismic activity in the region has been studied by many authors (e.g., Bezzeghoud et al., 2008; Borges et al., 2008).

As shown in Fig. 1a, the Azores consists of nine islands distributed among three different groups: the islands of Flores and Corvo, constituting the Western Group; the islands of Terceira, Graciosa, São Jorge, Faial and Pico, which are part of the Central Group; and the islands of São Miguel and Santa Maria in the Eastern Group.

Figure 1b shows epicenters in the Azores between 1915 and 2011, and Fig. 1c shows a zoomed-in map of epicenters of the islands.

The aim of this study is to define the seismic zones of the Azores, which will later be used for seismic simulations of the region.

We define several zones that express differences in seismicity, while allowing for a model that is not overly complex. Seismic zones are defined by polygons that delineate areas of homogeneous seismicity characteristics. They are also based on differences in geology and tectonics, but seismicity is the main characteristic in defining them (e.g., Reiter, 1991; Kagan et al., 2010).

In this work, the main criterion to define the zones is the recorded seismicity, as different zones should exhibit different statistical characteristics. The number of events is the most important variable used in this study; magnitude is also used, although large events may be infrequent.

Nunes et al. (2000) delineated a 28-seismic-zone model based on the distribution of epicenters and on the tectonics of Azores region. Due to the lack of seismic data, the model was simplified for use in hazard assessment to include nine main zones in order to allow a reliable statistical characterization of the model (Carvalho et al., 2001).

With the upgrade of the seismological network in the Azores in recent decades, seismic data have become more reliable and complete for magnitudes greater than $M_{\mathrm{L}}=3$. This allows for more robust statistical analyses than were possible in the past.

The seismic zones cover geophysical units where data are available. For each unit, we computed the following:

- The number of events. 




(a)

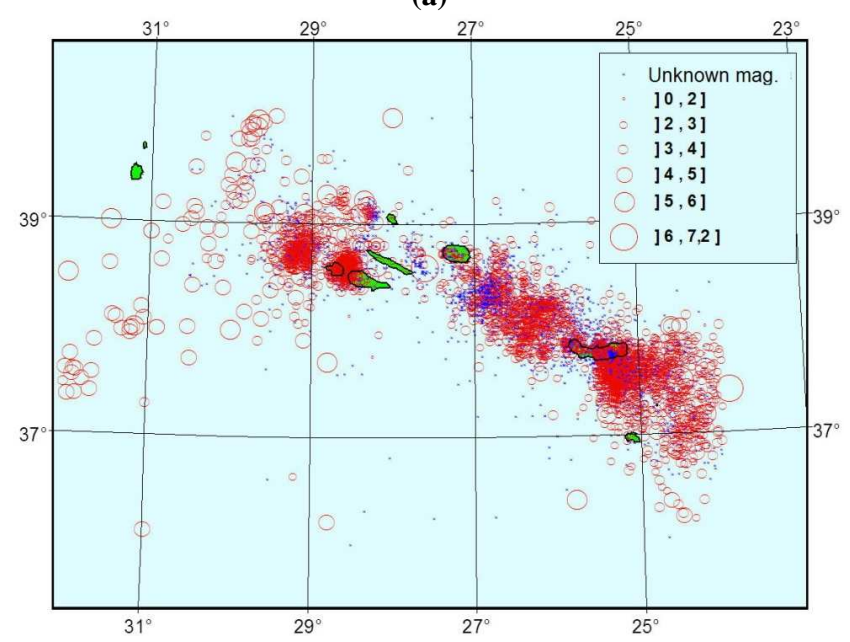

(b)

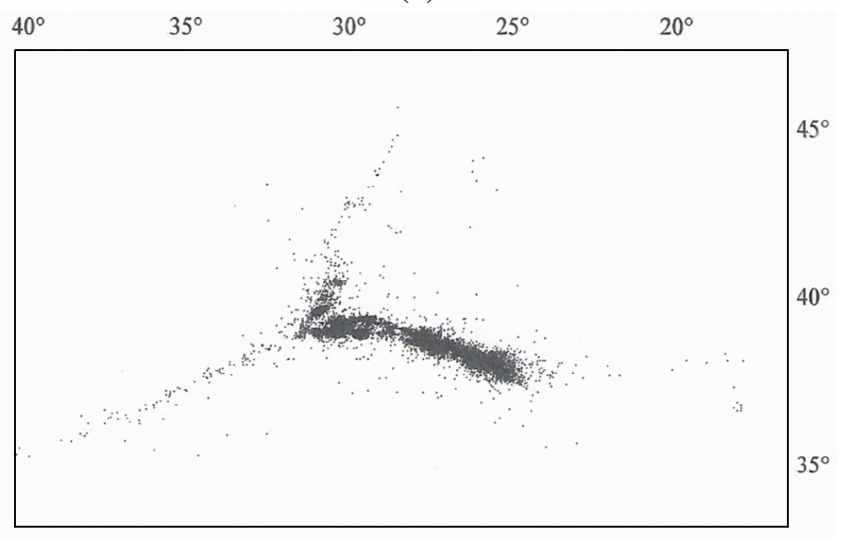

(c)

Fig. 1. (a) The Azores Archipelago, (b) epicentral map for 19152011 and (c) zoom of epicenters for the islands.

- The maximum magnitude recorded.

We grouped the 28 areas of Nunes et al. (2000) into seven zones that exhibit different characteristics. We used several statistic tests (parametric and nonparametric) to confirm whether these seven zones were significantly different.

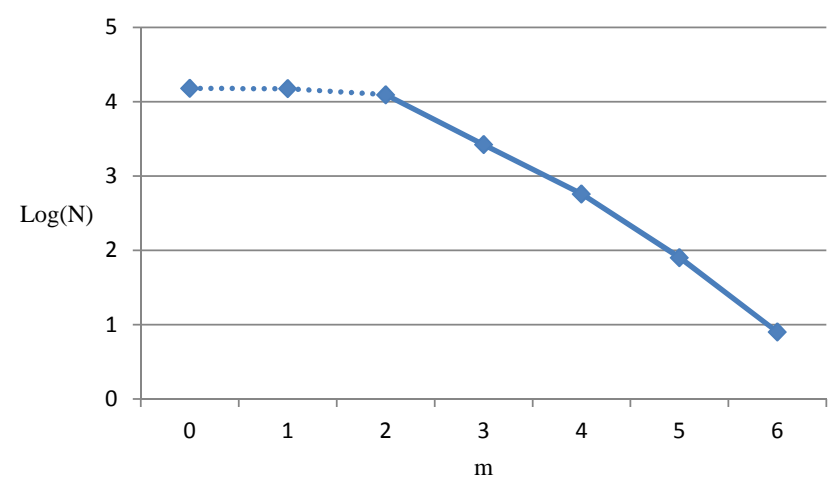

Fig. 2. Gutenberg-Richter plot for the Azores region showing all catalog seismicity.

\section{Data}

The data used in this work were gathered from two sources. For the period 1915-1998, we used the catalog of Nunes et al. (2004), and for the period 1999-2011, data were directly obtained from Instituto de Meteorologia (2011).

The earlier period covers the region encompassed by $11.50^{\circ} \mathrm{W}-42.86^{\circ} \mathrm{W}$ and $10.80^{\circ} \mathrm{N}-47.54^{\circ} \mathrm{N}$. A total of 9214 earthquake records are available, of which 5456 have information on Richter-scale magnitudes.

The catalog for the later period covers the area within $21.31^{\circ} \mathrm{W}-35.42^{\circ} \mathrm{W}$ and $34.30^{\circ} \mathrm{N}-45.57^{\circ} \mathrm{N}$, and contains 9608 earthquakes, all of which include magnitude information.

Table 1 summarizes the main characteristics of the data used.

The data were analyzed as a whole, including foreshocks and aftershocks. Fig. 2 shows a Gutenberg-Richter plot, which indicates that the dataset is not complete. Many small-magnitude events occur in the sea, far from the seismic network, and thus are not recorded. According to the Gutenberg-Richter law, a linear trend should exist between $\log N$ and $m$ :

$\log N(m)=a-b \times m$,

where $N$ is the number of events of magnitude greater than $m$, and $a$ and $b$ are constants fitted to the data.

Removing earthquakes smaller than magnitude 2, a leastsquares approximation leads to

$\log N(m)=5.77611-0.79 \mathrm{~m}$,

with a correlation coefficient $R=-0.996$, which indicates a significant linear correlation and that the catalog is complete for earthquakes with magnitude larger than 2 .

If we consider only events with magnitudes greater than 2 , much of the dataset would be lost (the value 2 corresponds approximately to the 0.40 quantile of magnitude; see Table 4), and the aim of this paper is not to estimate the 
Table 1. Data characteristics.

\begin{tabular}{ll}
\hline Data characteristics & \\
\hline Period of time covered (in years) & 1915 to 2011 \\
Total number of records & 18822 \\
Records containing information of magnitude & 15065 \\
Records without information of magnitude & 3757 \\
Records containing information of magnitude and intensity & 499 \\
Records with intensity information and without information of magnitude & 247 \\
\hline
\end{tabular}

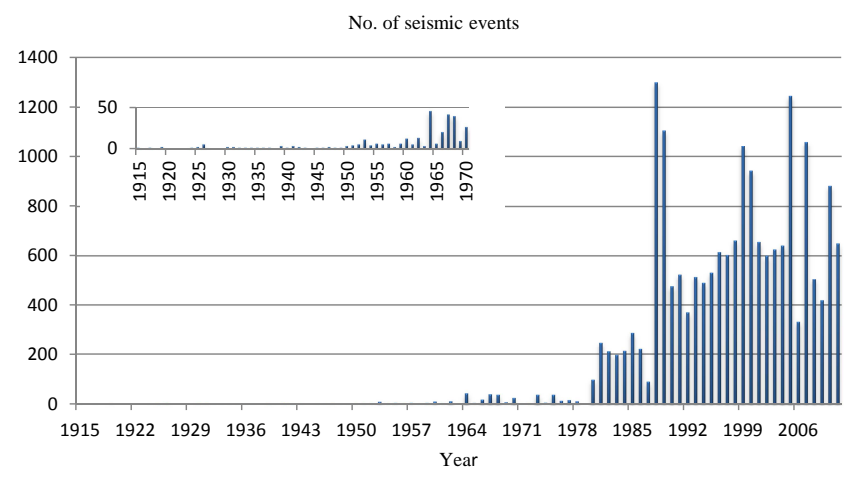

Fig. 3. Annual seismicity.

constants $a$ and $b$ of the Gutenberg-Richter law. Therefore, we consider all earthquakes with a catalog magnitude greater than 0 , which corresponds to events for which the magnitude has not been determined.

\section{Exploratory data analysis}

We used the $\mathrm{R}^{\circledR}$ software (e.g., Dalgaard, 2008; Venables et al., 2011) to perform the statistical analysis in this study. For some calculations, we also used the Turbo Pascal ${ }^{\circledR}$ software.

\subsection{Annual seismicity}

The seismic records contain information about the year, month, day, hour, minute and second of each event. For straightforward computation, time was converted into decimal years.

Consider the variable annual seismicity (AS), which represents the number of earthquakes that occurred in one year.

Figure 3 displays the AS for the period from 1915 to 2011.

The AS is very heterogeneous throughout the study period, and it appears to increase in 1960. This increase reflects the expansion of the seismic network in the Azores Archipelago.

Table 2 shows the main statistical properties of the AS for the period of 1915-2011.

Figure 4 shows a histogram of the AS, which is highly variable, varying between fewer than 200 earthquakes in one year to more than 1000 .
Table 2. Statistics of the AS.

\begin{tabular}{lr}
\hline Statistic & Value \\
\hline Mean & 200.39 \\
Standard deviation & 330.76 \\
Skewness & 1.63 \\
Kurtosis & 4.76 \\
Minimum & 0 \\
Quantile & \\
0.1 & 1 \\
0.2 & 1 \\
0.3 & 2 \\
0.4 & 4 \\
0.5 & 7 \\
0.6 & 28.6 \\
0.7 & 212.8 \\
0.8 & 499.8 \\
0.9 & 648.2 \\
1 (max.) & 1300 \\
Number of years & 95 \\
\hline
\end{tabular}

The heterogeneity of the data suggests that we should use records from 1960 onwards, as this produces a dataset that best reflects the actual seismicity.

\subsection{Statistical study of some characteristics of seismic events}

Each earthquake can be characterized by three variables: time, size and space.

The variable time (Dt) is characterized by the time intervals between consecutive earthquakes, the variable size $(S)$ is the Richter magnitude associated with an earthquake and the space variable ( $\mathrm{Sp}$ ) gives the number of the zone corresponding to the epicenter of the earthquake. However at this stage, $\mathrm{Sp}$ is characterized by the latitude and longitude of each earthquake.

Figure 5 describes a schematic representation of the seismic process of occurrences, where $S_{i}$ represents the size of earthquake $i, \mathrm{Dt}_{i}$ the time interval between this event and the preceding one $(i-1)$ and $\mathrm{Sp}_{i}$ the location of event $i$. 


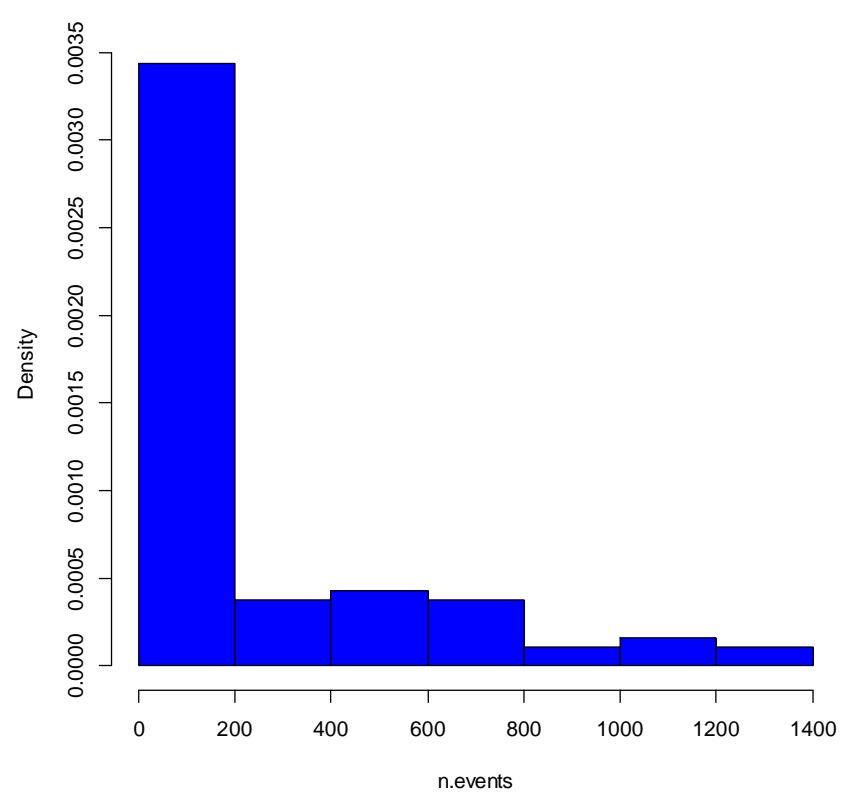

Fig. 4. Histogram of the number of seismic events per year.



Fig. 5. Schematic representation of the seismic process of occurrences.

\subsubsection{Study of the time variable}

As previously stated, Dt represents the time intervals between consecutive earthquakes, expressed in years, during the time period of $1915-2011$. Let $\mathrm{Dt}_{60}$ be the variable that typifies the time intervals between consecutive earthquakes between 1960 and 2011.

Table 3 shows the statistics of the variables $\mathrm{Dt}$ and $\mathrm{Dt}_{60}$, with the largest difference observed in their maximum values. While the maximum value of Dt is approximately $5 \mathrm{yr}$, the maximum value of $\mathrm{Dt}_{60}$ is only $0.78 \mathrm{yr}$, which is less than nine months. The mean Dt is approximately half of the mean $\mathrm{Dt}_{60}$. Comparing the quantiles of these two variables, there is no significant difference below the 0.90 quantile, indicating that the major difference is in the maximum values of the variables.

Figure 6a and b present the histograms of $\mathrm{Dt}$ and $\mathrm{Dt}_{60}$, respectively, which show clear difference between the two random variables.



(a)



(b)

Fig. 6. (a) Histogram of Dt, and (b) histogram of $\mathrm{Dt}_{60}$.

\subsubsection{Study of the size variable}

As described in Sect. 3.2.1, $S$ represents the size of each earthquake between 1915 and 2011.

As shown in Table 1, 3757 seismic records do not include magnitude; the magnitudes are null values in the catalog. If these records are not removed, they will influence the statistics of $S$.

In addition, if the earthquakes with null magnitudes were ignored, the time intervals between consecutive events would increase. 
Table 3. Statistics of Dt and $\mathrm{Dt}_{60}$.

\begin{tabular}{lrlr}
\hline Statistics of Dt & & Statistics of $\mathrm{Dt}_{60}$ & \\
\hline Mean & 0.0050207 & Mean & 0.0027532 \\
Standard deviation & 0.0632967 & Standard deviation & 0.0180847 \\
Skewness & 44.61 & Skewness & 24.8 \\
Kurtosis & 2823.92 & Kurtosis & 798.7 \\
Minimum & 0.00000000 & Minimum & 0.00000000 \\
\hline Quantile & & Quantile & \\
0.1 & 0.00000770 & 0.1 & 0.00000760 \\
0.2 & 0.00003982 & 0.2 & 0.00003884 \\
0.3 & 0.00011980 & 0.3 & 0.00011790 \\
0.4 & 0.00027390 & 0.4 & 0.00027020 \\
0.5 & 0.00053885 & 0.5 & 0.00053270 \\
0.6 & 0.00093420 & 0.6 & 0.00091922 \\
0.7 & 0.00157952 & 0.7 & 0.00155820 \\
0.8 & 0.00263610 & 0.8 & 0.00260176 \\
0.9 & 0.00492949 & 0.9 & 0.00479008 \\
1 (max.) & 5.0392669 & 1 (max.) & 0.77849250 \\
\hline Total number of records & 18821 & Total number of records & 18733 \\
\hline
\end{tabular}

Let $S_{w 0}$ represent the earthquake magnitudes, excluding the zero values of each earthquake between 1915 and 2011.

Table 4 summarizes the statistics calculated for $S$ and $S_{w 0}$.

As expected, $S_{w 0}$ has a larger mean than $S$, and the standard deviation of $S_{w 0}$ is less than for $S$. The quantiles of $S_{w 0}$ are greater than similar quantiles of $S$, except for the 1.0 quantile (maximum).

Figure 7 a presents a histogram of the absolute frequencies of $S$. The large number of zero magnitudes is due to earthquakes with unknown magnitudes.

The histogram displayed in Fig. 7b shows the asymmetry of the probability density function of $S_{w 0}$, with a significant tail for large values of $S_{w 0}$ and a positive skewness coefficient.

\section{Definition of seismic zones}

As previously described, the main goal of this study is to identify regions with significant differences in seismicity. We use the number of events and the maximum magnitude recorded to identify these differences. The region included in the dataset was divided into $1^{\circ} \times 1^{\circ}$ area units, and the number of earthquakes recorded in the period from 1915 to 2011 was computed for each area unit. Let $\mathrm{Sq}$ represent the number of events between 1915 and 2011 in each area unit.

Figure $8 \mathrm{a}$ shows the values of $\mathrm{Sq}$ for the region bounded by $40^{\circ} \mathrm{W}-15^{\circ} \mathrm{W}$ and $30^{\circ} \mathrm{N}-47^{\circ} \mathrm{N}$.

There is a band of increased seismicity (values above the 0.8 quantile of AS) with an approximately WNW-ESE orientation, which covers the Eastern and Central groups of the Azores Archipelago, as well as the NW Faial region, the trench west of Graciosa, the D. João de Castro Bank and the Hirondelle Trench.

However, for roughly half of this band, there is a slight decrease in the AS of the region bounded by $36^{\circ} \mathrm{N}-39^{\circ} \mathrm{N}$ and $27^{\circ} \mathrm{W}-28^{\circ} \mathrm{W}$.

A region with high values of $\mathrm{AS}$, although lower than for the WNW-ESE band, is oriented approximately SSW-NNE, and includes the islands of the Western Group and the northern Mid-Atlantic Ridge.

East of the WNW-ESE band, there is a region with nearly E-W orientation, in which the AS is also elevated.

The maximum magnitude recorded was also computed for each area unit during the study period.

Figure $8 \mathrm{~b}$ shows that the WNW-ESE and SSW-NNE bands of seismicity also have higher maximum recorded magnitudes, with the largest magnitude, 8.2 , recorded in the E-W band.

In the WNW-ESE band, two centers of high magnitudes are highlighted, one of which covers the Central Group of the Archipelago, particularly the western region of Faial Island, and the other covers the Eastern Group of the Archipelago, with an emphasis on São Miguel Island.

The seismic zones were defined by aggregating area units according to the aforementioned patterns, with an emphasis on the seismicity and the maximum magnitude recorded. Differences in geomorphology were also taken into account.

In the region within $11.50^{\circ} \mathrm{W}-42.54^{\circ} \mathrm{W}, 10.80^{\circ} \mathrm{N}-$ $47.54^{\circ} \mathrm{N}$, the following seven seismic zones were defined (Table 5, Fig. 9a and b):

Zone 1 comprises the Western Group of the Azores Archipelago and is situated NW of the Mid-Atlantic Ridge. It presents low values of seismicity, and the maximum 
Table 4. Statistics of $S$ and $S_{w 0}$.

\begin{tabular}{lrlr}
\hline Statistics of $S$ & \multicolumn{3}{l}{ Statistics of $S_{w 0}$} \\
\hline Mean & 2.05 & Mean & 2.56 \\
Standard deviation & 1.19 & Standard deviation & 0.68 \\
Skewness & -0.45 & Skewness & 1.11 \\
Kurtosis & 2.88 & Kurtosis & 6.21 \\
Minimum & 0.0 & Minimum & 0.2 \\
\hline Quantile & & Quantile & \\
0.1 & 0.0 & 0.1 & 2.0 \\
0.2 & 0.5 & 0.2 & 2.1 \\
0.3 & 2.0 & 0.3 & 2.2 \\
0.4 & 2.1 & 0.4 & 2.3 \\
0.5 & 2.3 & 0.5 & 2.4 \\
0.6 & 2.4 & 0.6 & 2.6 \\
0.7 & 2.6 & 0.7 & 2.8 \\
0.8 & 2.9 & 0.8 & 3.0 \\
0.9 & 3.2 & 0.9 & 3.4 \\
1 (max.) & 8.2 & 1 (max.) & 8.2 \\
\hline Total number of records & 1822 & Total number of records & 15065 \\
\hline
\end{tabular}

Table 5. Seismic zones.

\begin{tabular}{|c|c|c|}
\hline Zone & Definition & Designation \\
\hline Zone 1 & $\begin{array}{l}{[\text { lat } \leq 39 \text { and }} \\
\text { lat } \geq(\text { long }+70)] \text { OR } \\
{[\text { lat }>39 \text { and long } \leq(-31)]}\end{array}$ & West of Mid-Atlantic Ridge \\
\hline Zone 2 & $\begin{array}{l}{[\text { lat } \leq 39 \text { and lat }<(\text { long }+70) \text { and lat } \geq(\text { long }+68)] \text { OR }} \\
{[\text { lat }>39 \text { and long }>(-31) \text { and }} \\
\text { lat } \geq(\text { long }+68)]\end{array}$ & Mid-Atlantic Ridge \\
\hline Zone 3 & $\begin{array}{l}\text { lat } \geq(-0.4 \times \text { long }+28.2) \text { and } \\
\text { lat }<(\text { long }+68) \text { and } \\
\text { lat } \geq 38\end{array}$ & Northeast of Mid-Atlantic Ridge \\
\hline Zone 4 & $\begin{array}{l}\text { lat }<(-0.4 \times \text { long }+28.2) \\
\text { and lat } \geq(-0.2 \times \text { long }+32) \text { and lat }<(\text { long }+68) \\
\text { and lat } \geq(1.5 \times \text { long }+78.75)\end{array}$ & Azores Island Central Group \\
\hline Zone 5 & $\begin{array}{l}\text { lat }<(1.5 \times \text { long }+78.75) \text { and } \\
\text { long } \leq(-24.5) \text { and } \\
\text { lat }<(-0.4 \times \text { long }+28.2) \text { and } \\
\text { lat } \geq(-0.833 \times \text { long }+14.583)\end{array}$ & Azores Island Eastern Group \\
\hline Zone 6 & long $>(-24.5)$ and lat $<38$ and lat $\geq 35$ & Gloria Fault \\
\hline Zone 7 & $\begin{array}{l}\text { lat }<(-0.2 \times \text { long }+32) \text { and } \\
\text { lat }<(\text { long }+68) \text { and } \\
\text { lat }<(-0.833 \times \text { long }+14.583)\end{array}$ & South of Azores Islands \\
\hline
\end{tabular}




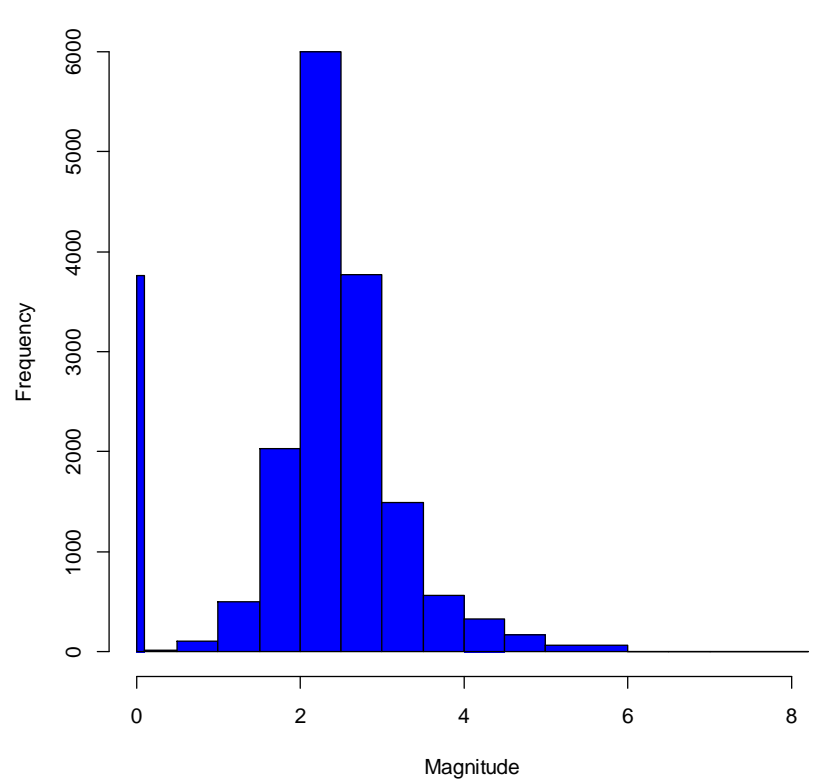

(a)

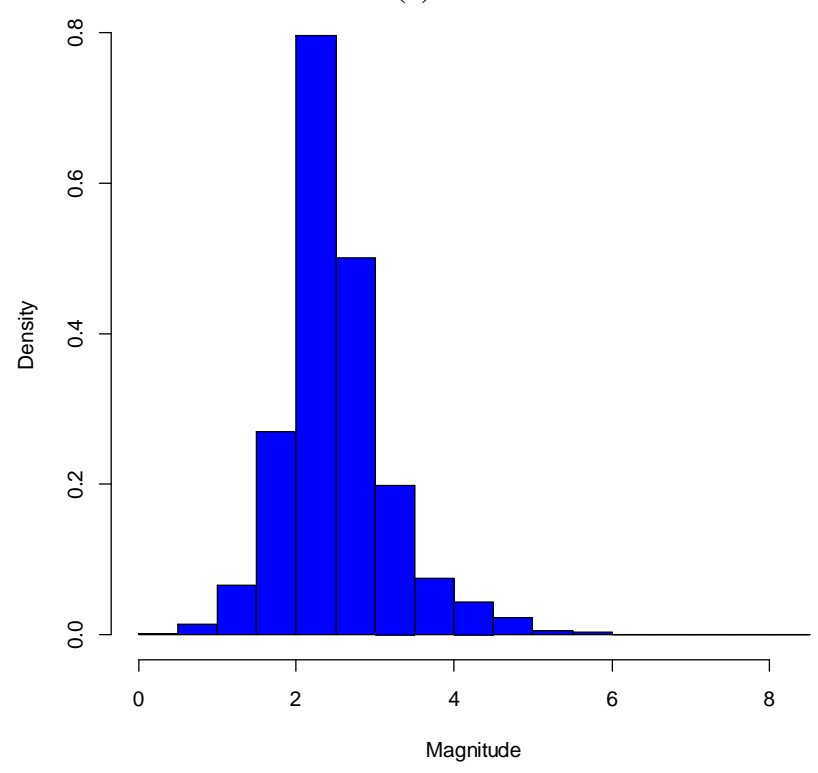

(b)

Fig. 7. (a) Histogram of absolute frequencies of $S$, and (b) histogram of $S_{w 0}$.

magnitude recorded is 6.2. The islands of Flores and Corvo are in this zone.

Zone 2 is a maritime zone corresponding to the MidAtlantic Ridge and its transform faults to the north. This zone also comprises the North Azores Fracture Zone. It has high levels of seismicity and a maximum magnitude of 6.0.

Zone 3 is a maritime zone with very low seismicity, located NE of the Central and Eastern groups of the Archipelago and east of the Mid-Atlantic Ridge. The maximum magnitude recorded is 4.7 , the lowest maximum magnitude for all zones.
Zone 4 encompasses the Central Group of the Archipelago, west of Capelinhos and the Terceira Rift central sector. It features very high seismicity and a maximum magnitude of 6.0. Compared to the maximum magnitudes recorded in other zones, this magnitude is not very high, indicating that the main characteristic of this zone is the high seismicity and not its maximum magnitude. This zone contains five islands: Faial, Pico, São Jorge, Terceira and Graciosa.

Zone 5 comprises the Eastern Group of the Archipelago, the Hirondelle Trench and the D. João de Castro Bank. It has the highest seismicity of all seven zones, and the maximum magnitude recorded is 7.0. This zone is characterized not only by its high seismicity but also by its high maximum magnitude recorded. This zone contains two islands: São Miguel and Santa Maria.

Zone 6 is a maritime zone and includes the Gloria Fault. The seismicity is moderate, but this zone has the highest magnitude of all zones: 8.2. It is characterized by a moderate number of earthquakes, which can be of relatively high magnitude.

Zone 7 is a maritime zone and is the furthest south of all seismic zones. It has the lowest seismicity, and the maximum magnitude recorded is 6.1 .

Zones 1, 3 and 7 include small numbers of events compared to the other seismic zones. Therefore, they are considered to be background zones.

The statistical study focuses primarily on zones 2, 4, 5 and 6 , although all zones were examined initially.

We calculated the number of earthquakes recorded between 1915 and 2011 for each seismic zone. Table 6 and Fig. 10 summarize the results.

\subsection{Statistical study of the time and size variables for each seismic zone}

In the statistical study of the time variable, characterized by the time intervals between consecutive events, only the period 1960-2011 was considered.

For the size variable, data from all time periods were considered, but the null values were not taken into consideration.

\subsubsection{Time}

Consider $\operatorname{Dt}_{60, i}, i \in\{1,2,3,4,5,6,7\}$, the variable that represents the time interval between an event and its previous event, both in zone $i$, in 1960 and later.

Table 7 summarizes the statistics calculated for $\mathrm{Dt}_{60, i}, i \in$ $\{1,2,3,4,5,6,7\}$.

\subsubsection{Size}

Let $S_{w 0, i}$ represent the nonzero magnitudes in the zone $i$, $i \in\{1,2,3,4,5,6,7\}$.

Table 8 condenses the statistics computed for $S_{w 0, i}, i \in$ $\{1,2,3,4,5,6,7\}$. 


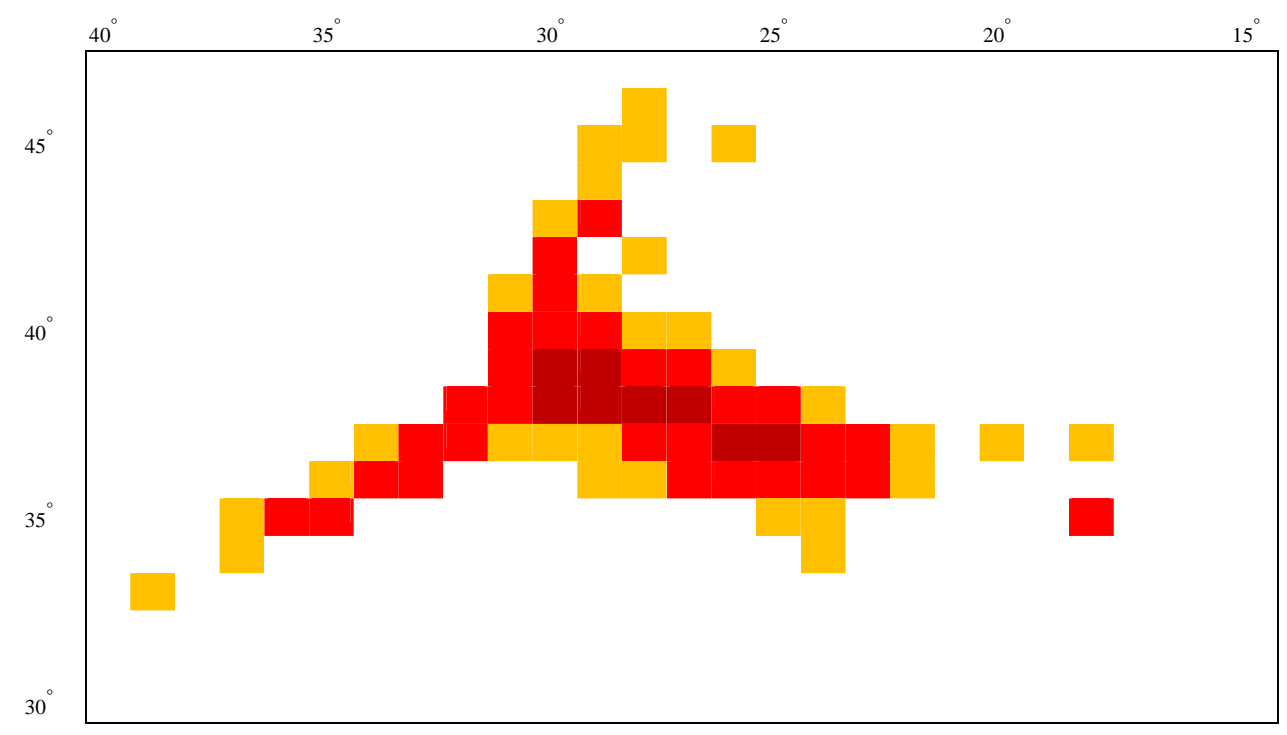

AS - Annual Seismicity; $\quad$ Sq-Seismicity recorded per area unit.

\begin{tabular}{|l|ll|}
\hline $\mathrm{Sq}<0.25$ quantile of AS & {$[0,1.9[$} \\
0.25 quantile of $\mathrm{AS} \leq \mathrm{Sq}<0.50$ quantile of AS & {$[2,6.9[$} \\
0.50 quantile of $\mathrm{AS} \leq \mathrm{Sq}<0.80$ quantile of AS & {$[7,499[$} \\
$\mathrm{Sq} \geq 0.80$ quantile of AS & {$[500,+\infty[$} \\
\hline
\end{tabular}

(a)

\begin{tabular}{|c|c|c|c|c|c|c|c|c|c|c|c|c|c|c|c|c|c|c|c|c|c|c|c|c|c|c|}
\hline & $40^{\circ}$ & & & & & $35^{\circ}$ & & & & & $30^{\circ}$ & & & & & $25^{\circ}$ & & & & & $20^{\circ}$ & & & & & $15^{\circ}$ \\
\hline \multirow{7}{*}{$45^{\circ}$} & 0 & 0 & 0 & 0 & 0 & 0 & 0 & 0 & 0 & 0 & 0 & 0 & 0 & 0 & 0 & 0 & 0 & 0 & 0 & 0 & 0 & 0 & 0 & 0 & 0 & 0 \\
\hline & 0 & 0 & 0 & 0 & 0 & 0 & 0 & 0 & 0 & 0 & 0 & 0 & 5.0 & 0 & 0 & 0 & 0 & 0 & 0 & 0 & 0 & 0 & 0 & 0 & 0 & 0 \\
\hline & 0 & 0 & 0 & 0 & 0 & 0 & 0 & 0 & 0 & 0 & 0 & 5.2 & 5.8 & 0 & 5.4 & 6.2 & 0 & 0 & 0 & 0 & 0 & 0 & 0 & 0 & 0 & 0 \\
\hline & 0 & 0 & 0 & 0 & 0 & 0 & 0 & 0 & 5.6 & 0 & 0 & 4.9 & 4.7 & 0 & 5.4 & 3.7 & 0 & 0 & 0 & 0 & 0 & 0 & 0 & 0 & 0 & 0 \\
\hline & 0 & 0 & 0 & 0 & 0 & 0 & 0 & 0 & 4.5 & 4.2 & 5.1 & 5.2 & 0 & 0 & 0 & 0 & 0 & 0 & 0 & 0 & 0 & 0 & 0 & 0 & 0 & 0 \\
\hline & 0 & 0 & 0 & 0 & 0 & 0 & 0 & 0 & 0 & 4.9 & 5.6 & 0 & 4.4 & 0 & 3.7 & 0 & 0 & 0 & 0 & 0 & 0 & 0 & 0 & 0 & 0 & 0 \\
\hline & 0 & 0 & 0 & 0 & 0 & 0 & 0 & 0 & 0 & 5.6 & 5.0 & 4.7 & 4.0 & 0 & 0 & 0 & 0 & 0 & 0 & 0 & 0 & 0 & 0 & 0 & 0 & 0 \\
\hline \multirow[t]{5}{*}{$40^{\circ}$} & 0 & 0 & 0 & 0 & 0 & 0 & 0 & 0 & 0 & 4.7 & 5.6 & 4.3 & 3.8 & 2.6 & 0 & 0 & 0 & 0 & 0 & 0 & 0 & 0 & 0 & 0 & 0 & 0 \\
\hline & 0 & 0 & 0 & 0 & 0 & 0 & 0 & 0 & 0 & 4.9 & 5.9 & 6.0 & 3.9 & 3.2 & 3.4 & 4.0 & 0 & 0 & 0 & 0 & 0 & 0 & 0 & 0 & 0 & 0 \\
\hline & 0 & 0 & 0 & 0 & 0 & 0 & 0 & 0 & 5.6 & 5.0 & 5.7 & 5.7 & 6.0 & 5.8 & 3.3 & 4.6 & 3.3 & 0 & 0 & 0 & 0 & 0 & 0 & 0 & 0 & 4.7 \\
\hline & 0 & 0 & 0 & 0 & 0 & 0 & 5.0 & 5.0 & 5.1 & 4.8 & 4.6 & 2.6 & 4.1 & 5.9 & 5.1 & 7.0 & 5.0 & 4.2 & 3.8 & 0 & 5.2 & 8.2 & 5.2 & 0 & 1.1 & 0 \\
\hline & 0 & 0 & 0 & 0 & 0 & J.1 & 4.9 & 5.1 & 0 & 0 & 2.3 & 4.5 & 3.1 & 2.7 & 5.9 & 5.3 & 5.3 & 5.6 & 4.5 & 0 & 0 & 0 & 0 & 0 & 0 & 0 \\
\hline \multirow[t]{5}{*}{$35^{\circ}$} & 0 & 0 & 0 & 4.7 & 6.2 & 6.1 & 4.5 & 0 & 0 & 0 & 0 & 0 & 0 & 0 & 3.2 & 4.0 & 3.7 & 0 & 0 & 0 & 0 & 0 & 6.5 & 0 & 0 & 0 \\
\hline & 0 & 0 & 5.1 & 5.0 & 5.2 & 0 & 0 & 4.9 & 4.2 & 0 & 0 & 0 & 0 & 0 & 0 & 0 & 4.7 & 3.2 & 0 & 0 & 0 & 0 & 0 & 0 & 0 & 0 \\
\hline & 0 & J.0 & 0 & 0 & 0 & 4.7 & 4.8 & 0 & 0 & 0 & 0 & 0 & 0 & 0 & 0 & 0 & 0 & 0 & 0 & 0 & 0 & 0 & 0 & 4.0 & 0 & 0 \\
\hline & 0 & 0 & 0 & 0 & 0 & 0 & 0 & 0 & 0 & 0 & 0 & 0 & 0 & 0 & 0 & 0 & 0 & 0 & 0 & 0 & 0 & 0 & 0 & 0 & 0 & 0 \\
\hline & 0 & 0 & 0 & 0 & 0 & 0 & 0 & 0 & 0 & 0 & 0 & 0 & 0 & 0 & 0 & 0 & 0 & 0 & 0 & 0 & 0 & 0 & 0 & 0 & 0 & 0 \\
\hline $30^{\circ}$ & 0 & 0 & 0 & 0 & 0 & 0 & 4.3 & 0 & 0 & 0 & 0 & 0 & 0 & 0 & 0 & 0 & 0 & 0 & 0 & 0 & 0 & 0 & 0 & 0 & 0 & 0 \\
\hline
\end{tabular}

Mmc - Maximum magnitude recorded per area unit.

\begin{tabular}{|l|l|}
\hline & Mmc $<4$ \\
$4 \leq \mathrm{Mmc}<5$ \\
$5 \leq \mathrm{Mmc}<6$ \\
$\mathrm{Mmc} \geq 6$
\end{tabular}

(b)

Fig. 8. (a) Seismicity recorded per area unit, and (b) maximum magnitude recorded per area unit. 


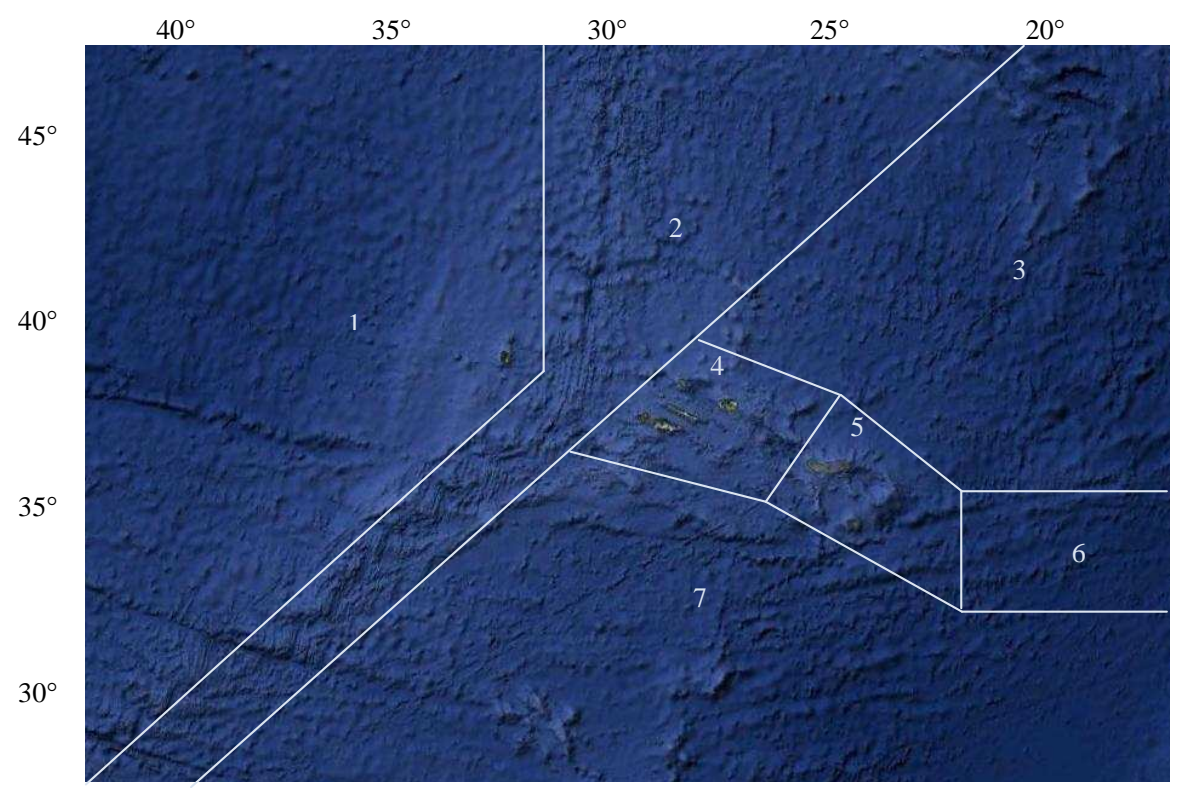

(a)

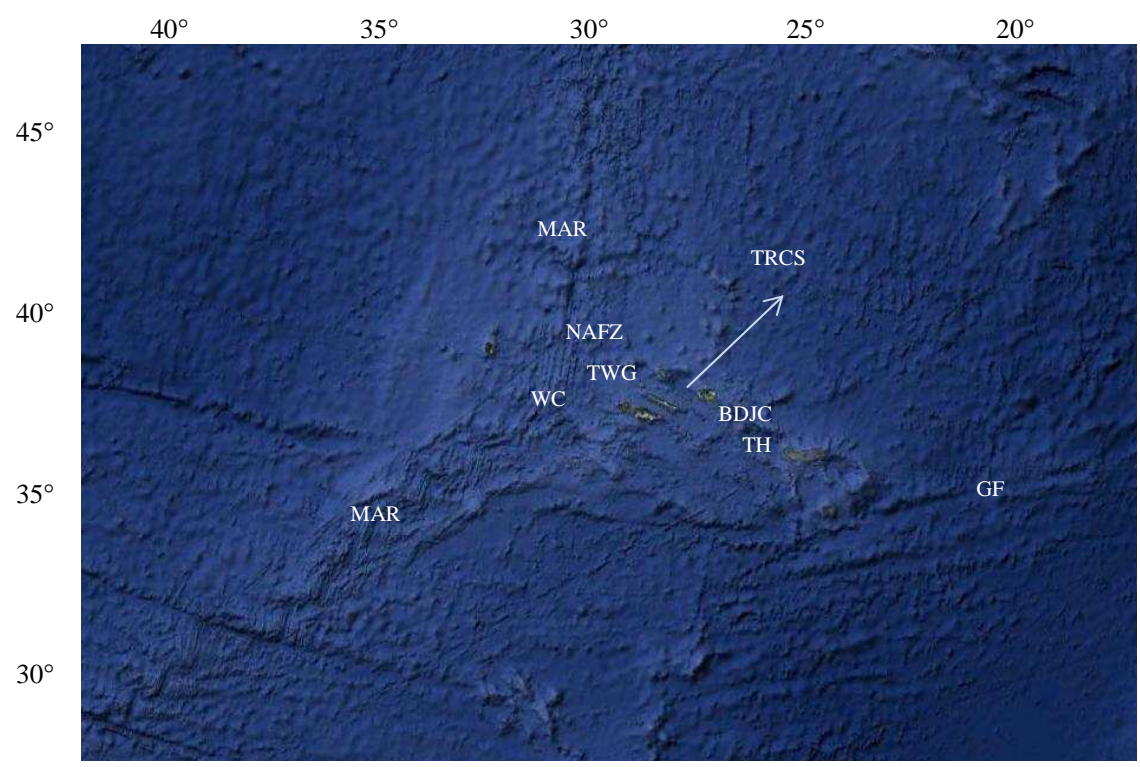

Mid-Atlantic Ridge (MAR); West of Capelinhos (WC); North Azores Fracture Zone (NAFZ); Bank D. João de Castro (BDJC); Trench Hirondelle (TH); Trench West of Graciosa (TWG); Terceira Rift Central Sector (TRCS); Gloria Fault (GF).

(b)

Fig. 9. (a) Schematic representation of the defined zones, and (b) morphological features of the study area.

Table 6. The number of seismic events in each seismic zone.

\begin{tabular}{lrrrrrrrr}
\hline Zone & 1 & 2 & 3 & 4 & 5 & 6 & 7 & Total \\
\hline Obs. & 201 & 1847 & 65 & 6009 & 9948 & 727 & 25 & 18822 \\
\hline
\end{tabular}


Table 7. Statistics of $\mathrm{Dt}_{60, i}$.

\begin{tabular}{rrrrrrr}
\hline & Mean & Standard deviation & Number of records & Minimum & Maximum & 95\% confidence interval for the mean \\
\hline $\mathrm{Dt}_{60,1}$ & 0.2683907 & 0.5484976 & 192 & 0.0000000 & 3.6578259 & {$[0.1907628,0.3460186]$} \\
$\mathrm{Dt}_{60,2}$ & 0.0281624 & 0.1090001 & 1831 & 0.0000000 & 1.7924995 & {$[0.0231697,0.0331551]$} \\
$\mathrm{Dt}_{60,3}$ & 0.8320763 & 1.6549227 & 60 & 0.0004793 & 10.6083954 & {$[0.4133231,1.2508295]$} \\
$\mathrm{Dt}_{60,4}$ & 0.0085003 & 0.0671134 & 5981 & 0.0000000 & 2.4777918 & {$[0.0067994,0.0102012]$} \\
$\mathrm{Dt}_{60,5}$ & 0.0051966 & 0.0462983 & 9921 & 0.0000000 & 2.3838838 & {$[0.0042855,0.0061077]$} \\
$\mathrm{Dt}_{60,6}$ & 0.0631802 & 0.2491379 & 720 & 0.0000019 & 4.9323605 & {$[0.0449820,0.0813784]$} \\
$\mathrm{Dt}_{60,7}$ & 2.2769963 & 2.1647580 & 22 & 0.0566912 & 8.3945568 & {$[1.3170182,3.2369744]$} \\
\hline
\end{tabular}

Table 8. Statistics of $S_{w 0, i}$.

\begin{tabular}{rrrrrrr}
\hline & Mean & Standard deviation & Number of records & Minimum & Maximum & 95\% confidence interval for the mean \\
\hline$S_{w 0,1}$ & 4.5 & 0.7 & 174 & 2.8 & 6.2 & {$[4.4,4.6]$} \\
$S_{w 0,2}$ & 3.0 & 0.7 & 1703 & 1.4 & 6.0 & {$[3.0,3.0]$} \\
$S_{w 0,3}$ & 2.9 & 0.6 & 38 & 2.0 & 4.7 & {$[2.7,3.1]$} \\
$S_{w 0,4}$ & 2.5 & 0.5 & 5407 & 0.2 & 6.0 & {$[2.5,2.5]$} \\
$S_{w 0,5}$ & 2.4 & 0.7 & 7087 & 0.2 & 7.0 & {$[2.4,2.4]$} \\
$S_{w 0,6}$ & 2.9 & 0.7 & 642 & 2.0 & 8.2 & {$[2.8,3.0]$} \\
$S_{w 0,7}$ & 4.1 & 1.2 & 14 & 1.9 & 6.1 & {$[3.4,4.8]$} \\
\hline
\end{tabular}

\section{Methodology for the dissimilation of seismic zones}

For the region covered by the data, area units were aggregated by their identical characteristics, resulting in the seven distinct zones.

In the following tests, the aim was to quantitatively show whether the variables corresponding to these areas were significantly different.

If the variables time, size and seismic conditions, which will be explained latter, differ significantly for each defined area, then statistical tests must indicate that these samples come from different populations.

As the seismic zones 1, 3 and 7 are markedly different from other areas based on their reduced seismicity, they are considered to be background zones. It was unnecessary to carry out statistical tests for these zones, and our statistical study focuses on zones 2, 4, 5 and 6 .

\subsection{Statistical tests}

Zones 2, 4, 5 and 6 were first studied together. We used a chisquare test for $r$ independent samples to investigate whether the $r$ populations from which $r$ samples were extracted were the same; that is, we tested the null hypothesis of the variables corresponding to the different zones being taken from the same population.

If the test conclusion was a clear rejection of the null hypothesis, it would not be necessary to use additional tests for $r$ samples, otherwise we must use, for example, the KruskalWallis test (see Siegel and Castellan, 1988).
If a nonparametric test for $r$ samples leads to the rejection of the null hypothesis, the variables cannot come from the same population, but it remains unclear as to whether all come from distinctly different populations. To investigate whether there are samples with the same distribution, we can compare any pair of the $r$ samples using a nonparametric test for pairs of samples.

In this case, we can use the chi-square test for two independent samples or the Kolmogorov-Smirnov two-sample test (e.g., Conover, 1999), with the latter preferable because it is more powerful; see Appendix A2 for a detailed description of these methods.

\section{Experiments carried out}

\subsection{Testing differences in time}

The chi-square test for $r$ independent samples was used to verify whether the samples formed by $\mathrm{Dt}_{60, j}, j \in\{2,4,5,6\}$ can be extracted from the same population.

Null hypothesis, H0: $\mathrm{Dt}_{60,2}, \mathrm{Dt}_{60,4}, \mathrm{Dt}_{60,5}$ and $\mathrm{Dt}_{60,6}$ have the same distribution.

Alternative hypothesis, $\mathrm{H1}: \mathrm{Dt}_{60,2}, \mathrm{Dt}_{60,4}, \mathrm{Dt}_{60,5}$ and $\mathrm{Dt}_{60,6}$ do not have the same distribution.

The data may be grouped into classes. Ten classes bounded by the deciles of $\mathrm{Dt}_{60}$ have been adopted (see Table 3 ).

The meanings of $O_{i j}, E_{i j}, C_{k}$ and $n_{r}$ are explained in Appendix A1. 
Table 9. Summary of results obtained in the chi-square test of time variable.

\begin{tabular}{|c|c|c|c|c|c|c|c|c|c|c|c|c|}
\hline Zone & & Class 1 & Class 2 & Class 3 & Class 4 & Class 5 & Class 6 & Class 7 & Class 8 & Class 9 & Class 10 & $n_{r}$ \\
\hline \multirow[t]{2}{*}{2} & $O_{i j}$ & 87 & 224 & 185 & 139 & 97 & 76 & 93 & 86 & 102 & 742 & 1831 \\
\hline & $E_{i j}$ & 166.0 & 173.0 & 151.0 & 144.1 & 133.2 & 131.3 & 136.1 & 140.5 & 184.9 & 470.9 & \\
\hline \multirow[t]{2}{*}{4} & $O_{i j}$ & 269 & 436 & 504 & 552 & 526 & 575 & 550 & 548 & 640 & 1381 & 5981 \\
\hline & $E_{i j}$ & 542.3 & 565.3 & 493.3 & 470.6 & 435.0 & 428.8 & 444.7 & 459.0 & 603.8 & 1538.3 & \\
\hline \multirow[t]{2}{*}{5} & $O_{i j}$ & 1314 & 1078 & 821 & 747 & 706 & 652 & 706 & 757 & 1075 & 2065 & 9921 \\
\hline & $E_{i j}$ & 899.5 & 937.6 & 818.3 & 780.6 & 721.5 & 711.3 & 737.6 & 761.3 & 1001.6 & 2551.6 & \\
\hline \multirow[t]{2}{*}{6} & $O_{i j}$ & 3 & 6 & 12 & 14 & 13 & 20 & 23 & 25 & 46 & 558 & 720 \\
\hline & $E_{i j}$ & 65.3 & 68.0 & 59.4 & 56.7 & 52.4 & 51.6 & 53.5 & 55.2 & 72.7 & 185.2 & \\
\hline$C_{k}$ & & 1673 & 1744 & 1522 & 1452 & 1342 & 1323 & 1372 & 1416 & 1863 & 4746 & 18453 \\
\hline
\end{tabular}

The results obtained in the chi-square test (Table 9) reveal significant differences between the observed and expected values, leading to the rejection of the null hypothesis.

The computation of the test statistic by Eq. (A1) $-T=$ 441301 with a 0.95 quantile of $\chi_{27}^{2}$ of 40.11 and a 0.99 quantile of 46.96 - indicates that we should reject the null hypothesis. As expected, we can conclude that the samples do not have the same distribution.

Given the large difference between the critical values and the test statistic, it was not necessary to carry out more tests using multiple samples.

The rejection of the null hypothesis only means that the samples do not have the same distribution, but they do not determine whether the samples have distinctly different distributions.

In cases such as this, Siegel and Castellan (1988) recommend investigating whether there are any samples with the same distribution. For this purpose, it is adequate to use the Kolmogorov-Smirnov two-sample test, in which we compare $C_{2}^{4}=6$ pairs of samples.

\section{Hypothesis}

H0: $\mathrm{Dt}_{60, i}, \mathrm{Dt}_{60, j}, i \in\{2,4,5\}, j \in\{4,5,6\}, i \neq j$ have the same distribution.

H1: $\mathrm{Dt}_{60, i}, \mathrm{Dt}_{60, j}, i \in\{2,4,5\}, j \in\{4,5,6\}, i \neq j$ do not have the same distribution.

Test statistics were computed using Eq. (A3). Table 10 summarizes the obtained results.

In all comparisons, the null hypothesis was rejected; that is, the statistical distributions of the variables $\mathrm{Dt}_{60, i}, i \in$ $\{2,4,5,6\}$ are different.

However, for the comparison of zones 4 and 5, the test statistic is equal to the critical value for a significance level of $1 \%$. This means that although the empirical distributions of these two populations differ significantly, the difference is smaller than that obtained for other pairs of samples.

To dispel any doubt concerning the possible (but unlikely) similarity between the distributions of $\mathrm{Dt}_{60,4}$ and $\mathrm{Dt}_{60,5}$, a parametric test using the average of these two variables was conducted. The $t$ test for two populations (variances unknown and unequal) (see Kanji, 1993) allows testing if the mean of the two variables may be considered equal. For details on $t$ tests, see Appendix A3.

The test can be applied because the size of the samples is large.

Let $\mu_{4}$ and $\mu_{5}$ be the means of the variables $\mathrm{Dt}_{60,4}$ and $\mathrm{Dt}_{60,5}$.

\section{Null hypothesis}

H0: $\mu_{4}=\mu_{5}$.

The test statistic $t$ has a Student's $t$ distribution with $v$ degrees of freedom. Applying Eqs. (A6) and (A7), one obtains, respectively, $t=3.356$ and $v=9436$.

The Student's $t$ variable with $n$ degrees of freedom approaches the standard normal distribution as $n$ approaches infinity. Let $Z_{1-\alpha / 2}$ be the 1- $\alpha / 2$ quantile of the normal standard distributions: $Z_{0.975}=1.96$ and $Z_{0.995}=2.58$.

As $t$ is much greater than the critical value, the null hypothesis can be rejected for the significance levels of $5 \%$ and $1 \%$.

We conclude that the statistical distributions of $\mathrm{Dt}_{60, i}, i \in$ $\{2,4,5,6\}$ differ significantly.

\subsection{Testing differences in size}

As was performed for $\mathrm{Dt}_{60, j}, j \in\{2,4,5,6\}$, the variables $S_{w 0, i}, i \in\{2,4,5,6\}$ were compared as a whole using the chi-square test for independent samples, and pairs were later compared.

\section{Hypothesis}

H0: $S_{w 0,2}, S_{w 0,4}, S_{w 0,5}$ and $S_{w 0,6}$ have the same distribution;

H1: $S_{w 0,2}, S_{w 0,4}, S_{w 0,5}$ and $S_{w 0,6}$ do not have the same distribution.

Data can be grouped into classes. Ten classes bounded by the deciles of $S_{w 0}$ were adopted (see Table 4), but classes 1 and 2 were joined because they have few expected values. 
Table 10. Summary of results obtained in the Kolmogorov-Smirnov test for time.

\begin{tabular}{lrrrrrr}
\hline Zones compared & 2 and 4 & 2 and 5 & 2 and 6 & 4 and 5 & 4 and 6 & 5 and 6 \\
\hline$n_{1}$ & 1831 & 1831 & 1831 & 5981 & 5981 & 9921 \\
$n_{2}$ & 5981 & 9921 & 720 & 9921 & 720 & 720 \\
$D$ & 0.155 & 0.174 & 0.265 & 0.027 & 0.406 & 0.433 \\
\hline Critical value $(\alpha=0.05)$ & 0.036 & 0.035 & 0.060 & 0.022 & 0.054 & 0.052 \\
Conclusion & Rej. H0 & Rej. H0 & Rej. H0 & Rej. H0 & Rej. H0 & Rej. H0 \\
\hline Critical value $(\alpha=0.01)$ & 0.044 & 0.042 & 0.073 & 0.027 & 0.065 & 0.064 \\
Conclusion & Rej. H0 & Rej. H0 & Rej. H0 & Rej. H0 & Rej. H0 & Rej. H0 \\
\hline
\end{tabular}

Table 11 summarizes the results obtained for the chisquare test for independent samples.

Computing the test statistic using Eq. (A1), we obtain $T=1781.1$, with a 0.95 quantile of $\chi_{24}^{2}$ of 36.42 and a 0.99 quantile of 42.98; we reject the null hypothesis.

Therefore, $S_{w 0, i}, i \in\{2,4,5,6\}$ do not come from the same population.

To investigate whether the samples arise from the same population, they were compared in pairs using the Kolmogorov-Smirnov two-sample test.

\section{Null hypothesis}

H0: $S_{w 0, i}, \quad S_{w 0, j}, i \in\{2,4,5\}, j \in\{4,5,6\}, i \neq j$ have the same distribution;

H1: $S_{w 0, i}, S_{w 0, j}, i \in\{2,4,5\}, j \in\{4,5,6\}, i \neq j$ do not have the same distribution.

Table 12 summarizes the results obtained for the Kolmogorov-Smirnov test.

In all comparisons, the null hypothesis was rejected; that is, the statistical distributions of the variables $S_{w 0, i}, i \in$ $\{2,4,5,6\}$ are different, demonstrating that for the size variable, seismic zones differ significantly. In this case, performing additional tests is unnecessary.

\subsection{Testing seismic conditions dissimilarity}

For each seismic zone, all earthquakes belong to one of four seismic conditions:

1. A recent event (i.e., $\mathrm{Dt}_{60, i} \leq 0.50$ quantile of $\mathrm{Dt}_{60}$ ) with a magnitude that is not large (i.e., $S_{w 0, i} \leq 0.80$ quantile of $S_{w 0}$ );

2. Not a recent event (i.e., $\mathrm{Dt}_{60, i}>0.50$ quantile of $\mathrm{Dt}_{60}$ ) and with a large magnitude (i.e., $S_{w 0, i}>0.80$ quantile of $\left.S_{w 0}\right)$;

3. A recent event (i.e., $\left.\mathrm{Dt}_{60, i} \leq 0.50\right)$ with a large magnitude (i.e., $S_{w 0, i}>0.80$ quantile of $S_{w 0}$ );

4. Not a recent event (i.e., $\mathrm{Dt}_{60, i}>0.50$ quantile of $\mathrm{Dt}_{60}$ ) and with a magnitude that is not large (i.e., $S_{w 0, i} \leq$ 0.80 quantile of $S_{w 0}$ ) have the correct boundaries.
Number of seismic events in each seismic zone

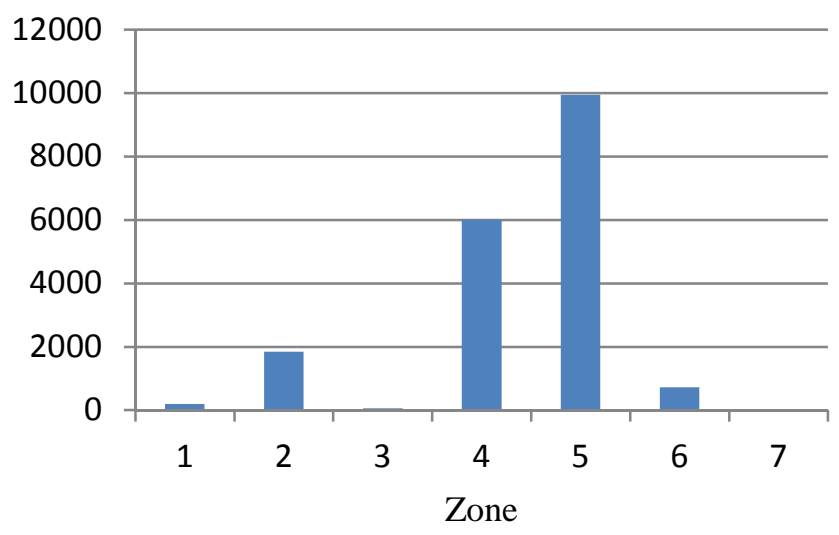

Fig. 10. A plot showing the number of seismic events in each seismic zone.

Let $\operatorname{cd}_{i}, i \in\{2,4,5,6\}$ represent the seismic condition of each earthquake that occurred in zone $i$. This variable can assume only values of $1,2,3$ and 4 , corresponding to the four seismic conditions.

Figure 11 summarizes the results obtained for zones 2, 4, 5 and 6.

To verify that the samples formed by $\operatorname{cd}_{i}, i \in\{2,4,5,6\}$ can be extracted from the same population, a chi-square test for independent samples was used.

Figure 11 strongly implies that the test leads to the rejection of the null hypothesis. Indeed, there is only some similarity in the distribution of $\mathrm{cd}_{i}$ in zones 4 and 5 .

\section{Hypothesis}

H0: $\mathrm{cd}_{i}, i \in\{2,4,5,6\}$ have the same distribution;

H1: $\operatorname{cd}_{i}, i \in\{2,4,5,6\}$ do not have the same distribution.

Table 13 summarizes the results obtained for the chisquare test.

Calculating the test statistic using Eq. (A1), we obtain $T=1810.4$, with a 0.95 quantile of $\chi_{9}^{2}$ of 16.92 and a 0.99 quantile of 21.67. Therefore, we reject the null hypothesis 
Table 11. Summary of results applying the chi-square test for size.

\begin{tabular}{llrrrrrrrrrr}
\hline Zone & & Class 1-2 & Class 3 & Class 4 & Class 5 & Class 6 & Class 7 & Class 8 & Class 9 & Class 10 & $n_{r}$ \\
\hline 2 & $O_{i j}$ & 44 & 44 & 66 & 84 & 180 & 268 & 241 & 348 & 428 & 1703 \\
& $E_{i j}$ & 304.2 & 150.7 & 150.0 & 143.6 & 243.5 & 208.0 & 160.9 & 180.1 & 162.0 & \\
4 & $O_{i j}$ & 820 & 633 & 582 & 524 & 785 & 698 & 511 & 507 & 347 & 5407 \\
& $E_{i j}$ & 966.0 & 478.4 & 476.2 & 455.8 & 773.2 & 660.3 & 510.9 & 571.7 & 514.5 & \\
5 & $O_{i j}$ & 1765 & 606 & 626 & 608 & 1067 & 765 & 565 & 587 & 498 & 7087 \\
& $E_{i j}$ & 1266 & 627 & 624 & 597 & 1013 & 865 & 670 & 749 & 674 & \\
6 & $O_{i j}$ & 22 & 30 & 33 & 35 & 90 & 81 & 85 & 127 & 139 & 642 \\
& $E_{i j}$ & 114.7 & 56.8 & 56.5 & 54.1 & 91.8 & 78.4 & 60.7 & 67.9 & 61.1 & \\
\hline \multirow{2}{*}{$C_{k}$} & & 2651 & 1313 & 1307 & 1251 & 2122 & 1822 & 1402 & 1569 & 1412 & 14839 \\
\hline
\end{tabular}

Table 12. Summary of results obtained in Kolmogorov-Smirnov test for size.

\begin{tabular}{lrrrrrr}
\hline Zones compared & 2 and 4 & 2 and 5 & 2 and 6 & 4 and 5 & 4 and 6 & 5 and 6 \\
\hline$n_{1}$ & 1703 & 1703 & 1703 & 5407 & 5407 & 7087 \\
$n_{2}$ & 5407 & 7087 & 642 & 7087 & 642 & 642 \\
$D$ & 0.373 & 0.414 & 0.082 & 0.136 & 0.297 & 0.335 \\
\hline Critical value $(\alpha=0.05)$ & 0.038 & 0.037 & 0.063 & 0.025 & 0.057 & 0.056 \\
Conclusion & Rej. H0 & Rej. H0 & Rej. H0 & Rej. H0 & Rej. H0 & Rej. H0 \\
\hline Critical value $(\alpha=0.01)$ & 0.046 & 0.045 & 0.076 & 0.030 & 0.069 & 0.068 \\
Conclusion & Rej. H0 & Rej. H0 & Rej. H0 & Rej. H0 & Rej. H0 & Rej. H0 \\
\hline
\end{tabular}
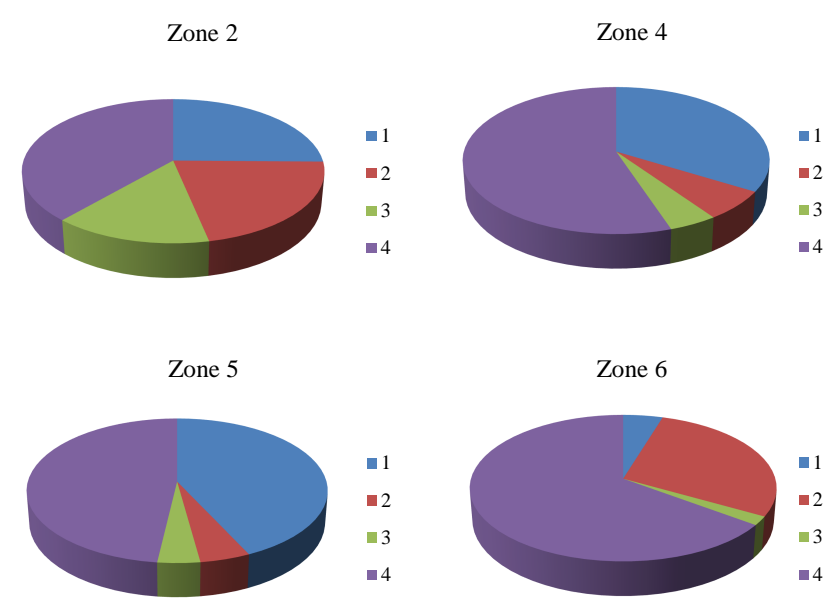

Fig. 11. Graphical representation of $\operatorname{cd}_{i}, i \in\{2,4,5,6\}$.

and conclude that the samples do not have the same distribution.

This means that the distributions of seismic conditions are not the same in zones 2, 4, 5 and 6.

To investigate whether samples of the seismic conditions are from the same population, they were compared in pairs using the Kolmogorov-Smirnov two-sample test.

\section{Hypothesis}

H0: $\operatorname{cd}_{i}, \operatorname{cd}_{j}, i \in\{2,4,5\}, j \in\{4,5,6\}, i \neq j$ have the same distribution;

H1: $\operatorname{cd}_{i}, \operatorname{cd}_{j}, i \in\{2,4,5\}, j \in\{4,5,6\}, i \neq j$ do not have the same distribution.

Table 14 summarizes the results obtained in the Kolmogorov-Smirnov test.

In all comparisons, the null hypothesis was rejected; that is, the statistical distributions of $\operatorname{cd}_{i}, i \in\{2,4,5,6\}$ are different, demonstrating that the seismic conditions of the seismic zones differ significantly.

We also tested the dissimilarity of seismic conditions using a similar procedure that differs only in using the $\mathrm{Dt}_{60}$ quantile of 0.80 instead of 0.50 . This provided similar results.

\section{Conclusions}

In this study, we defined seismic zones for the Azores region. We first divided the area into $1^{\circ} \times 1^{\circ}$ area units. For each area unit, the seismicity and maximum magnitude recorded were computed.

These two variables were used with the geological characteristics of the region to group area units with similar characteristics; we identified seven seismic zones.

Statistical tests, particularly goodness-of-fit tests, were used, allowing for us to conclude that the variables time, size 
Table 13. Summary of results applying the chi-square test for the seismic condition.

\begin{tabular}{llrrrrr}
\hline Zone & & $\mathrm{cd}_{1}$ & $\mathrm{~cd}_{2}$ & $\mathrm{~cd}_{3}$ & $\mathrm{~cd}_{4}$ & $n_{r}$ \\
\hline 2 & $O_{i j}$ & 462 & 393 & 270 & 706 & 1831 \\
& $E_{i j}$ & 672.5 & 145.6 & 95.3 & 917.6 & \\
4 & $O_{i j}$ & 2016 & 391 & 274 & 3300 & 5981 \\
& $E_{i j}$ & 2196.9 & 475.5 & 311.2 & 2997.5 & \\
5 & $O_{i j}$ & 4266 & 478 & 402 & 4775 & 9921 \\
& $E_{i j}$ & 3644.1 & 788.7 & 516.1 & 4972.1 & \\
6 & $O_{i j}$ & 34 & 205 & 14 & 467 & 720 \\
& $E_{i j}$ & 264.5 & 57.2 & 37.5 & 360.8 & \\
\hline \multirow{2}{*}{$C_{k}$} & & 6778 & 1467 & 970 & 9248 & 18453 \\
\hline
\end{tabular}

Table 14. Summary of results obtained in the Kolmogorov-Smirnov test for the seismic condition.

\begin{tabular}{lrrrrrr}
\hline Zones compared & 2 and 4 & 2 and 5 & 2 and 6 & 4 and 5 & 4 and 6 & 5 and 6 \\
\hline$n_{1}$ & 1831 & 1831 & 1831 & 5981 & 5981 & 9921 \\
$n_{2}$ & 5981 & 9921 & 720 & 9921 & 720 & 720 \\
$D$ & 0.166 & 0.178 & 0.263 & 0.093 & 0.290 & 0.383 \\
\hline Critical value $(\alpha=0.05)$ & 0.036 & 0.035 & 0.060 & 0.022 & 0.054 & 0.052 \\
Conclusion & Rej. H0 & Rej. H0 & Rej. H0 & Rej. H0 & Rej. H0 & Rej. H0 \\
\hline Critical value $(\alpha=0.01)$ & 0.044 & 0.041 & 0.072 & 0.027 & 0.064 & 0.063 \\
Conclusion & Rej. H0 & Rej. H0 & Rej. H0 & Rej. H0 & Rej. H0 & Rej. H0 \\
\hline
\end{tabular}

and seismic conditions describing the seven seismic zones differ significantly.

The results of this study will likely be used in future seismic modeling of occurrences in the region.

\section{Appendix A}

\section{Statistical tests}

\section{A1 Chi-square test for $r$ independent samples}

The data consist of $r$ independent random samples of sizes $n_{1}, n_{2}, \ldots n_{r}$.

Let $F_{1}(x), F_{2}(x), \ldots, F_{r}(x)$ represent their respective distribution functions. Each observation can be classified as exactly one of the $k$ categories or classes.

Null hypothesis (H0): $F_{1}(x)=F_{2}(x)=\ldots=F_{r}(x)$.

Let $O_{i j}$ represent the observed number of cells $(i, j)$. The total number of observations is denoted by $N$. Therefore, $N=n_{1}+n_{2}+\ldots+n_{r}$.

Let $C_{j}$ be the total number of observations in the $j$ th class $(j=1,2, \ldots, k)$, such that $C_{j}=O_{1_{j}}+O_{2_{j}}+\ldots+O_{r j}, j=$ $1,2, \ldots, k$.
Table A1. Notation used in the chi-square test for $r$ independent samples.

\begin{tabular}{llllll}
\hline Sample & Class 1 & Class 2 & $\ldots$ & Class $k$ & Totals \\
\hline 1 & $O_{11}$ & $O_{12}$ & $\ldots$ & $O_{1 k}$ & $n_{1}$ \\
2 & $O_{21}$ & $O_{22}$ & $\ldots$ & $O_{2 k}$ & $n_{2}$ \\
$\ldots$ & $\ldots$ & $\ldots$ & $\ldots$ & $\ldots$ & \\
$r$ & $O_{r 1}$ & $O_{r 2}$ & $\ldots$ & $O_{r k}$ & $n_{r}$ \\
\hline Totals & $C_{1}$ & $C_{2}$ & $\ldots$ & $C_{k}$ & $N$ \\
\hline
\end{tabular}

\section{Test statistic}

$$
\begin{array}{r}
T=\sum_{i=1}^{r} \sum_{j=1}^{k} \frac{\left(O_{i j}-E_{i j}\right)^{2}}{E_{i j}}, \\
\text { where } E_{i j}=\frac{n_{i} C_{j}}{N} .
\end{array}
$$

The term $E_{i j}$ represents the expected number of observations in cell $(i, j)$ if $\mathrm{HO}$ is true. That is, if $\mathrm{HO}$ is true, the number of observations in cell $(i, j)$ should be close to the $i$ th sample size $n_{i}$ multiplied by the proportion $C_{j} / N$.

It can be shown that the sampling distribution of $T$ is approximately chi-square distributed with

$(k-1) .(r-1)$ degrees of freedom, $\chi 2_{(k-1) .}(r-1)$.

Let $\alpha$ be the level of significance, i.e., the maximum probability of rejecting a true null hypothesis. 


\section{Decision rule}

Reject $\mathrm{H} 0$ if $T$ exceeds the $1-\alpha$ quantile of the variable $\chi_{(k-1)(r-1)}^{2}$; otherwise do not reject $\mathrm{H} 0$.

\section{A2 Kolmogorov-Smirnov two-sample test}

The Kolmogorov-Smirnov test checks whether two samples were extracted from the same population. The bilateral test is sensitive to any difference in location, dispersion or asymmetry.

The Kolmogorov-Smirnov test aims to assess agreement between two cumulative distribution functions.

The data consist of two independent random samples of sizes $n_{1}$ and $n_{2}$. Let $F_{1}(x)$ be the empirical distribution function based on the one random sample $X_{1}, X_{2}, \ldots, X_{n 1}$, and let $F_{2}(x)$ be the empirical distribution function based on the other random sample $Y_{1}, Y_{2}, \ldots, Y_{n 2}$. In order for this test to be precise, the variables must also be continuous.

Hypothesis: (two-sided test)

H0: $F_{1}(x)=F_{2}(x)$ for all $x$ from $-\infty$ to $+\infty$;

H1: $F_{1}(x) \neq F_{2}(x)$ for at least one value $x$.

Test statistic: for the two-sided test, the test statistic, $D$, is

$D=\sup _{x}\left|F_{1}(x)-F_{2}(x)\right|$.

Decision rule: reject $\mathrm{H} 0$ at the level of significance $\alpha$ if the test statistic, $D$, exceeds its $1-\alpha$ quantile.

For great samples and for $\alpha=0.05$, the $1-\alpha$ quantile of $D$ is

$1.36 \sqrt{\frac{n 1+n 1}{n 1 . n 2}}$,

and for $\alpha=0.01$, the (1- $\alpha)$ quantile of $D$ is

$1.63 \sqrt{\frac{n 1+n 1}{n 1 . n 2}}$.

\section{A3 $t$ test for two population means (variances unknown and unequal)}

Consider two populations with means of $\mu 1$ and $\mu 2$. Independent random samples of size $\mathrm{n}_{1}$ and $\mathrm{n}_{2}$ are taken from sets with means $\bar{x} 1$ and $\bar{x} 2$ and variances $s 1^{2}$ and $s 2^{2}$. The populations may be normally distributed, or the sample sizes may be sufficiently large (see Kanji, 1993).

Null hypothesis: $\mu 1=\mu 2$.

Test statistic: the variable

$t=\frac{(\bar{x} 1-\bar{x} 2)-(\mu 1-\mu 2)}{\left[\frac{s 1^{2}}{n 1}+\frac{s 2^{2}}{n 2}\right]^{\frac{1}{2}}}$

has a Student's $t$ distribution with $v$ degrees of freedom, given by

$v=\left\{\frac{\left[\frac{s 1^{2}}{n 1}+\frac{s 2^{2}}{n 2}\right]^{2}}{\frac{s 1^{4}}{n 1^{2}(n 1+1)}+\frac{s 2^{4}}{n 2^{2}(n 2+1)}}\right\}-2$.
Decision rule: reject $\mathrm{H} 0$ at the level of significance $\alpha$ if the absolute value of $t$ exceeds its $1-\alpha / 2$ quantile.

Acknowledgements. The authors would like to acknowledge the comments and recommendations made by two anonymous referees and to Oded Katz, Editor of NHESS, which allowed improvements to the original manuscript.

Edited by: O Katz

Reviewed by: two anonymous referees

\section{References}

Bezzeghoud, M., Borges, J. F., Caldeira, B., Buforn, E., and Udias, A.: Seismic Activity in the Azores region in the context of the Western part of the Eurasia-Nubia Plate boundary. Proc. International Seminar on Seismic Risk, Azores, Portugal, paper 7 (CDROM), 1-11, 2008.

Borges, J. F., Bezzeghoud, M., Caldeira, B., and Buforn, E.: Recent seismic activity in the Azores Region. Proc. International Seminar on Seismic Risk, Azores, Portugal, paper 8 (CDROM), 1-5, 2008.

Carvalho, A., Sousa, M. L., Oliveira, C. S., Campos-Costa, A., Nunes, J. C., and Forjaz, V. H.: Seismic hazard for Central Group of the Azores Islands, B. Geofis. Teor. Appl., 42, 89-105, 2001.

Conover, W. J.: Practical nonparametric statistics. John Wiley \& Sons, New York, 1999.

Dalgaard, P.: Introductory Statistics with R, Springer, New York, 2008.

Kagan, Y. Y., Bird, P., and Jackson, D. D.: Earthquake Patterns in Diverse Tectonic Zones of the Globe, Pure Appl. Geophys., 167, 721-741, 2010.

Kanji, G. K.: 100 Statistical Tests, London, SAGE Publications, 1993.

IM - Instituto de Meteorologia: available at: http://www.meteo.pt/ pt/sismologia/actividade/ (last access: January 2011), 2011.

Nunes J. C., Forjaz, V. H., and Oliveira, C. S.: Zonas de geração sísmica para o estudo da casualidade do Grupo Central do Arquipélago dos Açores, PPERCAS Project, Report no. 3/2000, Azores University, Ponta Delgada, Portugal, 2000.

Nunes, J. C., Forjaz, V. H., and Oliveira, C. S.: Catálogo Sísmico da Região dos Açores, Lisbon, Portugal, (CDROM), 2004.

Reiter, L.: Earthquake Hazard Analysis: Issues and Insights, Columbia University Press, USA, 1991.

Siegel, S. and Castellan, N. J.: Nonparametric statistics for the behavioral sciences, McGraw-Hill, New York, 1988.

Venables, W. N., Smith, D. M., and R Development Core Team: An Introduction to R, Notes on R: A Programming Environment for Data Analysis and Graphics, available at: http:// cran.r-project.org/doc/manuals/R-intro.pdf (last access: November 2012), 2011. 